\title{
Unhealthy Gambling Amongst New Zealand Secondary School Students: An Exploration of Risk and Protective Factors
}

\author{
Fiona V. Rossen ${ }^{1} \cdot{\text { Terryann } \text { Clark }^{2} \cdot \text { Simon J. Denny }}^{3}$ • \\ Theresa M. Fleming ${ }^{4} \cdot$ Roshini Peiris-John ${ }^{5}$. \\ Elizabeth Robinson $^{6}$ • Mathijs F. G. Lucassen ${ }^{7}$
}

Published online: 30 June 2015

(C) The Author(s) 2015. This article is published with open access at Springerlink.com

\begin{abstract}
This study sought to determine the prevalence of gambling and unhealthy gambling behaviour and describe risk and protective factors associated with these behaviours amongst a nationally representative sample of New Zealand secondary school students $(n=8,500)$. Factor
\end{abstract}

Fiona V. Rossen

f.rossen@auckland.ac.nz

Terryann Clark

t.clark@auckland.ac.nz

Simon J. Denny

s.denny@auckland.ac.nz

Theresa M. Fleming

t.fleming@auckland.ac.nz

Roshini Peiris-John

r.peiris-john@auckland.ac.nz

Elizabeth Robinson

e.robinson@auckland.ac.nz

Mathijs F. G. Lucassen

m.lucassen@auckland.ac.nz

1 Social and Community Health, School of Population Health, Faculty of Medical and Health Sciences, University of Auckland, Private Bag 92019, Auckland 1142, New Zealand

2 School of Nursing, University of Auckland, Auckland, New Zealand

3 Department of Paediatrics: Child and Youth Health, University of Auckland, Auckland, New Zealand

4 Department of Paediatrics: Child and Youth Health \& Department of Psychological Medicine, University of Auckland, Auckland, New Zealand

5 Section of Epidemiology and Biostatistics, University of Auckland, Auckland, New Zealand

6 Auckland UniServices Ltd, Auckland, New Zealand

7 Department of Psychological Medicine, University of Auckland, Auckland, New Zealand 
analysis and item response theory were used to develop a model to provide a measure of 'unhealthy gambling'. Logistic regressions and multiple logistic regression models were used to investigate associations between unhealthy gambling behaviour and selected outcomes. Approximately one-quarter $(24.2 \%)$ of students had gambled in the last year, and $4.8 \%$ had two or more indicators of unhealthy gambling. Multivariate analyses found that unhealthy gambling was associated with four main factors: more accepting attitudes towards gambling $(p<0.0001)$; gambling via gambling machines/casinos/track betting $(p=0.0061)$; being worried about and/or trying to cut down on gambling $(p<0.0001)$; and, having attempted suicide $(p=0.0009)$. Unhealthy gambling is a significant health issue for young people in New Zealand. Ethnic and social inequalities were apparent and these disparities need to be addressed.

Keywords Youth $\cdot$ Gambling $\cdot$ Risk factors $\cdot$ Protective factors $\cdot$ Mental Health

\section{Introduction}

Gambling is a widely available activity in industrialised societies; and an entire generation has grown up in an era when lottery and casino gambling is widely available and heavily advertised (Volberg, Gupta, Griffiths, Ólason, and Delfabbro 2010). Gambling has therefore become a popular pastime not only among adults, but also among children and young people (Derevensky and Gupta 2000; Splevins, Mireskandari, Clayton, and Blaszczynski 2010) with gambling being one of the first 'risky activities' that adolescents engage in, even prior to experimenting with alcohol and drugs, or engaging in sexual behaviour (Volberg et al. 2010). Youth gamblers engage in a range of gambling activities, from informal modes such as betting amongst friends, through to more formal activities such as 'fruit machines', electronic gambling machines (EGMs) and lottery-based products (Department of Internal Affairs 2008; Felsher, Derevensky, and Gupta 2003; Ipsos MORI, 2012; Stinchfield 2001; Turner, Macdonald, Bartoshuk, and Zangeneh 2008). Research has shown that access to this latter type of gambling remains accessible to young people, despite age-related restrictions (Department of Internal Affairs 2008; Fisher 1999; Rossen, Butler, and Denny 2011; Rossen, Tse, and Vaidya 2009). Research also suggests that gambling behaviour may change as young people progress developmentally, with accessible (but age-restricted) activities such as lottery products and EGMs becoming more attractive to older adolescents (Rossen et al. 2009; Stinchfield 2001; Volberg et al. 2010). It is worth noting that in New Zealand the legal age for gambling varies according to the specific activity, in particular: 20 years of age for casino gambling; and, 18 years of age for Instant Kiwi (scratch tickets), TAB (track and sports) betting and EGMs in pubs or clubs. With the exception of Instant Kiwi, there are currently no age limits on the various lottery products provided by Lotto New Zealand (a Crown Entity that was established in 1987).

Whilst for many young people involvement in gambling does not appear to have negative impacts on their health and wellbeing, research globally has documented that a sub-set of youth go on to experience serious problems (Hardoon and Derevensky 2002; Huang and Boyer 2007; Jackson, Dowling, Thomas, Bond, and Patton 2008; Turchi and Derevensky 2006; Volberg et al. 2010; Welte, Barnes, Tidwell, and Hoffman 2008) with those who start gambling at an earlier age more likely to develop more severe gambling problems (Huxley and Carroll 1992; Volberg, Abbott, Ronnberg, and Munck 2001). A recent review estimates that 4 
$8 \%$ of young people gamble at problem/pathological levels with a further $10-15 \%$ at risk of developing a gambling problem (Volberg et al. 2010). Rates of unhealthy gambling among young people is higher than that identified for adults, with some estimates of youth rates being at least double those of adults (Volberg et al. 2010).

The social and other costs of problem gambling experienced by young people have been widely reported in the literature. In particular, the co-existence of problem gambling and poor mental health has been noted, with depression and suicide attempts frequently associated with youth gambling (Derevensky and Gupta 2000; Volberg et al. 2010). The co-existence of problem gambling and engagement in other addictive behaviours has also been documented. For example, substance misuse is a significant risk factor for unhealthy youth gambling (Dickson, Derevensky, and Gupta 2008; Fisher 1999; Goldstein et al. 2013; Griffiths and Wood 2000; Moodie and Finnigan 2006; Rossen et al. 2011; Stinchfield 2000), with alcohol use being one of the strongest predictors of gambling amongst high school students in the United States (Stinchfield 2000). Disruptions to family relationships and other relationships, as a result of gambling, have also been reported in the literature (Blinn-Pike, Worthy, and Jonkman 2010; Fisher 1999; Floros, Siomos, Fisoun, and Geroukalis 2013; Hardoon, Derevensky, and Gupta 2002; Hardoon and Derevensky 2002; Splevins et al. 2010). Furthermore, as gambling progresses into problematic levels, friendships and relationships with nongambling peers may be replaced by gambling-related associates (Blinn-Pike et al. 2010; Fortune et al. 2013; Gupta and Derevensky 2000). As with other addictive behaviours, when a young person's gambling behaviour intensifies or becomes problematic, the young person may become increasingly socially isolated (Hardoon and Derevensky 2002; Splevins et al. 2010). Problem gambling amongst youth has also been associated with: delinquency and crime (Blinn-Pike et al. 2010; Clark and Walker 2009; Fortune et al. 2013; Gupta and Derevensky 2000; Valentine 2008); school-related difficulties (e.g. truancy and reduced academic performance) (Blinn-Pike et al. 2010; Dickson et al. 2008; Floros et al. 2015; Splevins et al. 2010); and, financial difficulties (Fisher 1999; Gupta and Derevensky 2000).

Despite previous research on risk factors associated with unhealthy gambling from overseas, to the best of the authors' knowledge no analysis of risk and protective factors of unhealthy gambling, based on data from population-based studies of adolescents in Australasia, is available in the peer-reviewed literature.

This study aimed to report the prevalence of unhealthy gambling behaviours and describe risk and protective factors associated with unhealthy gambling behaviours, amongst a recent and large nationally representative sample of high school students in New Zealand. A comprehensive understanding of the risk and protective factors associated with adolescent gambling will assist in health promotion efforts to improve awareness of youth gambling issues and related help-seeking behaviours. This is particularly important as young people tend to seek help for gambling-related problems from informal sources, such as friends and their family, rather than from professional healthcare providers (Griffiths 2001; Gupta and Derevensky 2000).

\section{Methods}

This study used data collected as part of Youth'12, the third national health and wellbeing survey of secondary school students in New Zealand conducted in 2012. A detailed description of the Youth'12 survey methodology is available elsewhere (Clark et al. 2013). In summary, 
8,500 randomly selected secondary school students throughout New Zealand took part in Youth'12. In total, 91 randomly selected high schools participated in the survey, accounting for $3 \%$ of the total 2012 secondary school roll in New Zealand. Response rates for schools and students were $73 \%$ and $68 \%$ respectively. The comprehensive 608-question survey was anonymous and administered via internet tablets (Denny et al. 2008). Written consent was required from each participating school and each student prior to participation. The University of Auckland Human Participants Ethics Committee approved the study.

\section{Measures}

Participants were asked "What sex are you?" (response options were "Male" or "Female") and they were asked to indicate their age in years. Due to small numbers for some analyses, age was categorised as ' 15 or less' and ' 16 or older'. This categorisation was chosen as it is consistent with the age that New Zealand adolescents can leave school (i.e. students can leave school at 16 years of age). Students indicated the ethnic group(s) that they belonged to. Response options were based on the New Zealand Census standard 2001/2006 ethnicity questions (Statistics New Zealand 2005) and participants who chose more than one ethnicity were assigned a single ethnic group based on the Statistics New Zealand ethnicity prioritization method (Lang 2002). Therefore for the present analyses ethnicity was grouped as: Māori, Pacific, Asian, "Other", and New Zealand European. Neighbourhood socio-economic deprivation was measured using the New Zealand Deprivation Index (NZDep2006) (Salmond, Crampton, Sutton, and Atkinson 2006 ) for the census area unit that the student lived in. NZDep2006 combines eight dimensions of deprivation derived from the NZ census (Salmond et al. 2006 ). For data analyses students were grouped into one of three deprivation bands lower deprivation (NZ census deprivation deciles 1 to 3), medium deprivation (deciles 4 to 7 ) and higher deprivation (deciles 8 to 10). A student's geography was divided into two categories, urban and rural.

For the purpose of this study, gambling was defined as having "bet precious things for money on an activity". Involvement in gambling was assessed by the question "Have you ever gambled or bet precious things for money on any of these activities?" with the following activities: "Instant Kiwi (scratchies)"; "Lotto (including Strike, Powerball and Big Wednesday)"; "Bingo or Housie"; "Pub or club pokies"; "A casino (e.g. roulette, pokies)"; "TAB betting (e.g. on track racing or sports)"; "Games and gambling on a cell/mobile phone for money or prizes (e.g. txt games)"; "Gambling on the Internet for money or prizes (e.g. internet casinos or poker)"; "Bets with friends or family"; "0900 phone games"; "Cards or coin games (e.g. poker)". Response options to these items included: "Never"; "Not in the past 12 months"; "Once or twice in the past 12 months"; "Once in the last 4 weeks"; "Two or three times in the last 4 weeks"; "About once a week"; "Several times a week"; and, "Most days".

Youth'12 is a comprehensive survey (with up to 608 questions) focused on youth health and wellbeing and as such it covers a wide range of domains or topics. While the survey aimed to include as many important questions as possible, we aimed to create a survey that could be completed within approximately one hour, thus preventing participant fatigue. As such, a validated problem gambling screen (e.g. the DSM-IV-MR-J) was not included in Youth'12. The absence of a problem gambling screen resulted in the authors developing a specific model to provide a measure of problematic or unhealthy gambling. This model was developed through an analysis of the previous national youth survey - Youth'07, where factor analysis 
was used to assess dimensionality of gambling behaviour and the number of underlying factors (Rossen et al. 2011). The relationship between a participant's responses to items and their level on the underlying latent gambling continuum were examined using two-parameter logistic item-response theory models. Item Response Theory (IRT) was used to model the probability of gambling behaviours along a latent dimension of 'less unhealthy' to 'more unhealthy' gambling behaviours. This allowed the development of a framework for evaluating which behaviours were more severe. The model utilised seven indicators of unhealthy gambling, including four reasons for gambling that are consistent with escapism and/or loss of control ("I gamble to relax"; "I gamble to feel better about myself"; "I gamble to forget about things"; "I gamble because I can't stop") and higher levels of engagement with or expenditure on gambling (gambling 'several times a week' or 'most days'; spending \$20 or more per week on gambling; and, spending one or more hours per day on gambling activities). Analyses indicated that it would be appropriate to utilise this model to provide a measure of 'unhealthy gambling' for the present study. Students were classified as having 'none', 'one' or 'two or more' indicators of unhealthy gambling. A full description of the development of this measure can be found in the associated Youth'07 report (Rossen et al. 2011). A description for all the outcome variables and measures that were utilised in this study are available from the first author upon request (of note, these variables were based on a comprehensive review of the gambling literature and consultation with an expert advisory group that guided the overall research project) (Rossen et al. 2013).

\section{Analyses}

All statistical analyses have accounted for the sample design and clustering effects within schools; data have been weighted by the inverse probability of selection and the variance of estimates were adjusted to allow for correlated data from the same schools. Total numbers and prevalence estimates, adjusted percentages, and $95 \%$ confidence intervals were calculated for the selected outcomes. Logistic regression and multiple logistic regression models were used to investigate the associations between unhealthy gambling behaviour and outcomes. Logistic regression models included the possible confounders of age, sex, ethnicity, urban/rural status and level of neighbourhood socioeconomic deprivation. All statistical analyses were carried out using SAS software (version 9.3) (SAS Institute Inc 2011). Given the sample size and number of comparisons, a p-value of $\leq 0.01$ was taken to indicate statistical significance.

\section{Results}

\section{Involvement in Gambling}

One-in-10 students had gambled in the last 4 weeks and almost one-quarter $(24.2 \%)$ had gambled in the last year (see Table 1). Overall, rates of gambling were spread across demographic variables such as age group, urban/rural setting, and level of neighbourhood deprivation. However, significantly greater proportions of males than females had gambled in the last 4 weeks and in the last year. There was also a significant association between ethnicity and gambling in the last 4 weeks with the non-New Zealand European students being proportionately more likely to gamble, and this was especially so for Māori and Pacific students. 
Table 1 Gambling in the past month and past year by demographic features

\begin{tabular}{|c|c|c|c|c|c|c|}
\hline & \multicolumn{3}{|c|}{ Gambled in the last 4 weeks } & \multicolumn{3}{|c|}{ Gambled in the last 12 months 1} \\
\hline & $\mathrm{n}(\mathrm{N})$ & $\%(95 \% \mathrm{CI})$ & p-value & $\mathrm{n}(\mathrm{N})$ & $\%(95 \% \mathrm{CI})$ & $\mathrm{p}$-value \\
\hline Total & $804(7,813)$ & $10.3(9.4-11.3)$ & & $1890(7,813)$ & $24.2(23.1-25.3)$ & \\
\hline \multicolumn{7}{|l|}{ Sex } \\
\hline Male & $440(3,456)$ & $12.8(11.7-13.8)$ & $<.0001$ & $911(3,456)$ & $26.4(24.7-28.1)$ & $<.0001$ \\
\hline Female & $363(4,355)$ & $8.4(7.4-9.3)$ & & $978(4,355)$ & $22.5(21.4-23.6)$ & \\
\hline \multicolumn{7}{|l|}{ Age } \\
\hline 15 or less & $529(5,033)$ & $10.6(9.4-11.7)$ & 0.6462 & $1,189(5,033)$ & $23.7(22.4-24.9)$ & 0.09 \\
\hline 16 or more & $273(2,770)$ & $9.8(8.6-11.1)$ & & $697(2,770)$ & $25.2(23.3-27.1)$ & \\
\hline \multicolumn{7}{|l|}{ Ethnicity } \\
\hline Māori & $180(1,490)$ & $12.1(10.4-13.8)$ & 0.0008 & $375(1,490)$ & $25.1(22.7-27.5)$ & 0.08 \\
\hline Pacific & $142(1,007)$ & $14.2(10.8-17.5)$ & & $264(1,007)$ & $26.3(23.2-29.3)$ & \\
\hline Asian & $91(983)$ & $9.3(7.9-10.8)$ & & $221(983)$ & $22.6(20.0-25.1)$ & \\
\hline Other & $55(474)$ & $11.6(8.5-14.7)$ & & $113(474)$ & $23.9(19.5-28.3)$ & \\
\hline NZ European & $335(3,852)$ & $8.7(7.5-9.9)$ & & $916(3,852)$ & $23.8(22.3-25.4)$ & \\
\hline \multicolumn{7}{|l|}{ NZDep2006 } \\
\hline Lower & $239(2,598)$ & $9.3(7.8-10.7)$ & 0.3063 & $639(2,598)$ & $24.7(22.6-26.7)$ & 0.52 \\
\hline Medium & $272(2,809)$ & $9.7(8.5-10.9)$ & & $667(2,809)$ & $23.8(22.1-25.4)$ & \\
\hline Higher & $286(2,327)$ & $12.4(10.5-14.2)$ & & $565(2,327)$ & $24.4(22.5-26.3)$ & \\
\hline \multicolumn{7}{|l|}{ Geography } \\
\hline Urban & $693(6,563)$ & $10.6(9.6-11.6)$ & 0.3121 & $1,580(6,563)$ & $24.1(23.0-25.3)$ & 0.54 \\
\hline Rural & $104(1,171)$ & $8.9(7.3-10.5)$ & & $291(1,171)$ & $24.8(22.2-27.5)$ & \\
\hline
\end{tabular}

1. The percentages reported here are inclusive of students who had gambled in the last 4 weeks

\section{Unhealthy Gambling Behaviour}

While the majority of students who had gambled in the last 12 months did not report any indicators of 'unhealthy gambling' $(84.3 \%, n=1557)$, approximately one-tenth $(11.0 \%, n=$ $203)$ reported one indicator and approximately five percent $(n=89)$ reported two or more indicators of 'unhealthy gambling' (see Table 2). Significant interactions were observed between the distribution of 'unhealthy gambling' indicators and sex (males more than females); ethnicity (Māori, Pacific and Asian students more than New Zealand European); and neighbourhood deprivation (living in highly deprived neighbourhoods more than lower deprivation neighbourhoods).

\section{Identification of Risk and Protective Factors}

Table 3 provides results from a series of logistic regression analyses between the measure of 'unhealthy gambling' behaviour and each of the hypothesised risk/protective factors (phase one analyses). In total, 24 variables were significantly associated with 'unhealthy gambling' behaviour; 22 were associated with an increased risk (e.g. being same/both-sex attracted or not-sure of one's sexual attractions) and two variables moderated/protected against the risk of 'unhealthy gambling' behaviour. In particular, good wellbeing (which was based on the WHO- 





$\overbrace{}^{0}$

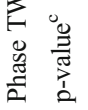

$\frac{\sqrt[n]{n}}{\frac{m}{2}}$

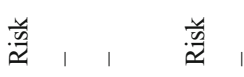

$\underset{\square}{\square} \frac{n}{0}$

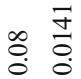

$\underset{8}{\bar{\delta}}$

$\begin{array}{llll}\overline{8} & 0 & 0 & 0 \\ 1 & 0 & 0 \\ 0\end{array}$

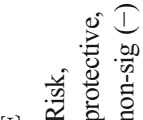

崩



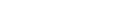

$\frac{x}{\frac{4}{2}} \frac{4}{2}$

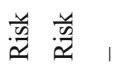

$\frac{\sqrt[4]{a}}{2}$

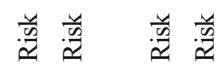

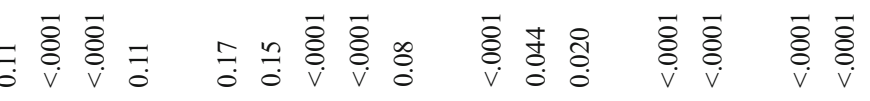

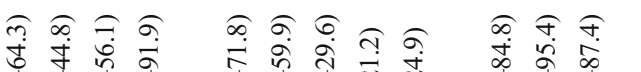



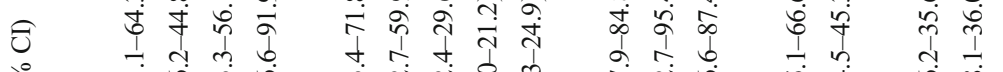

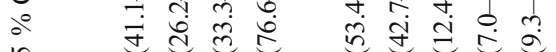

$\begin{array}{lll}\hat{2} & 0 \\ \hat{0} & \stackrel{0}{0} & 0 \\ 0 & 0 & 0\end{array}$



$\stackrel{n}{1}$ in

$\sum^{\circ} \circ^{\circ}$

m $m=-$

भु.

हें मे मेत्रे

$\sum_{0}$

$\begin{array}{ll}5 & \\ 0 & \infty \\ 3 & 11\end{array}$

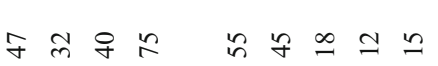

ำ

in $\bar{m}$

ง



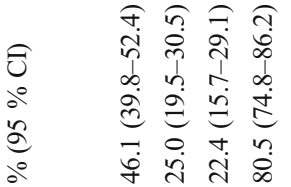

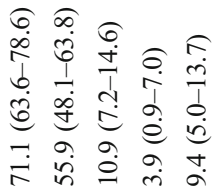

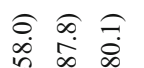

‡.

ศิ

t. 110

过点

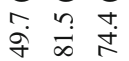

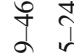

ल

त $r$ a

क्ष

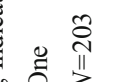

๙ँ

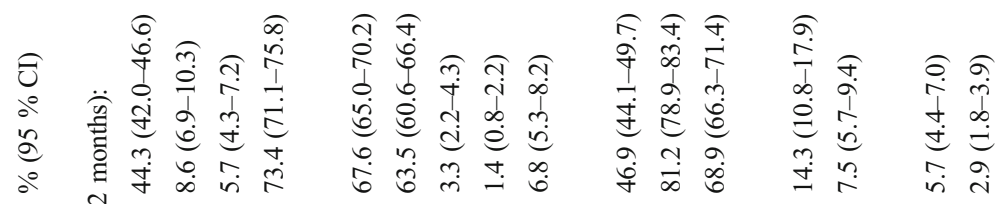

$\approx \odot$

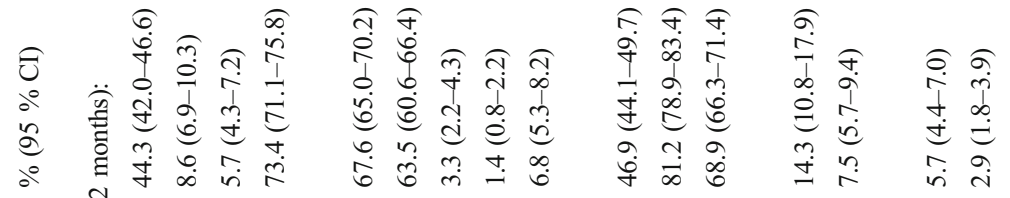
命 营

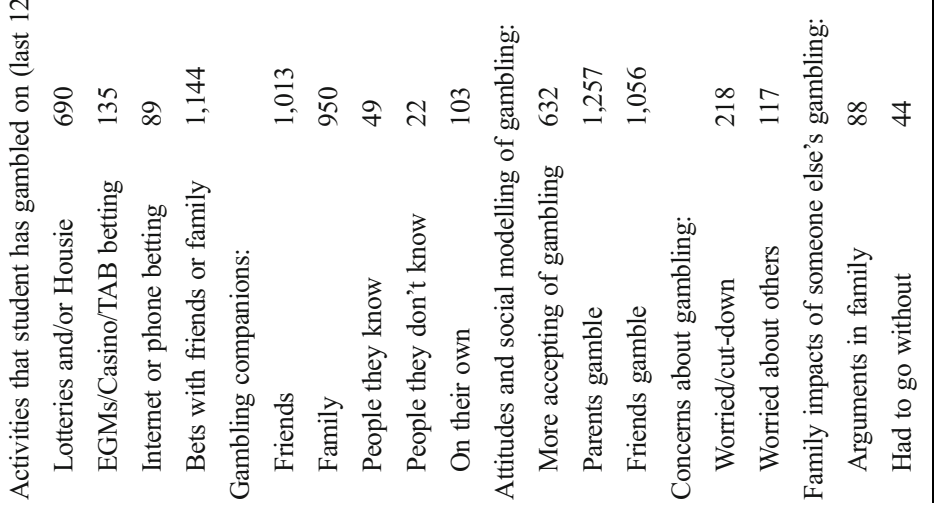




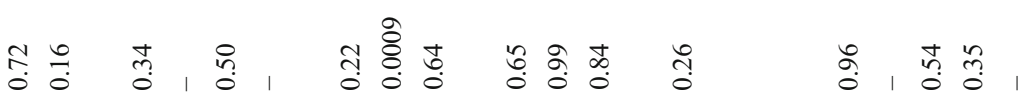

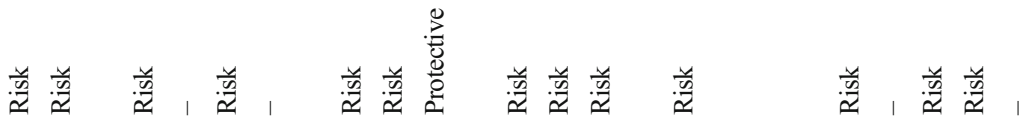

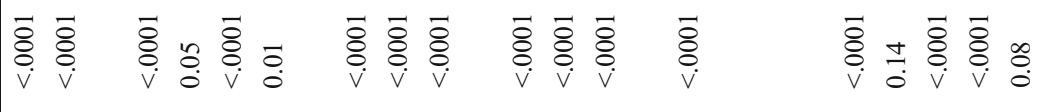

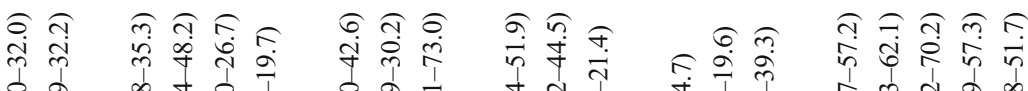

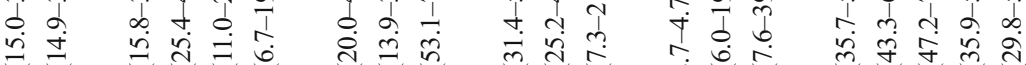


๗ֶ)

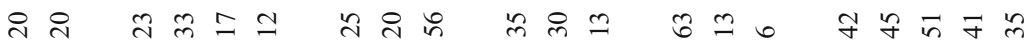



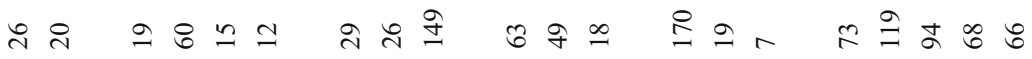

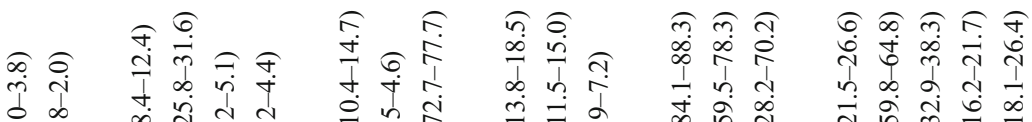

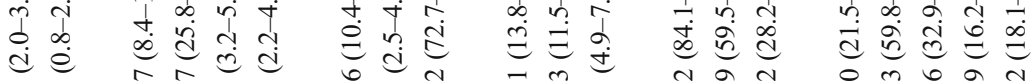

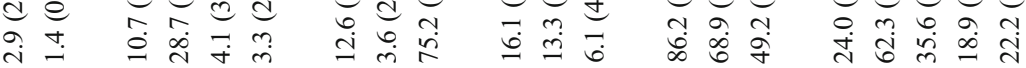



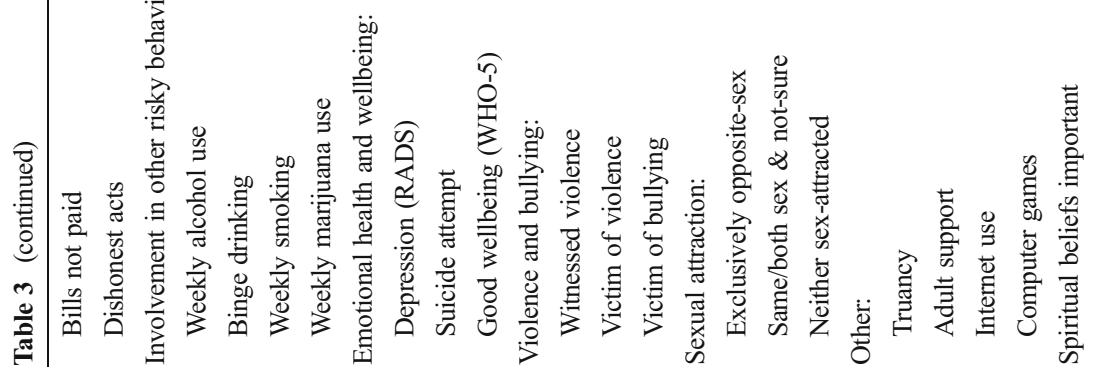




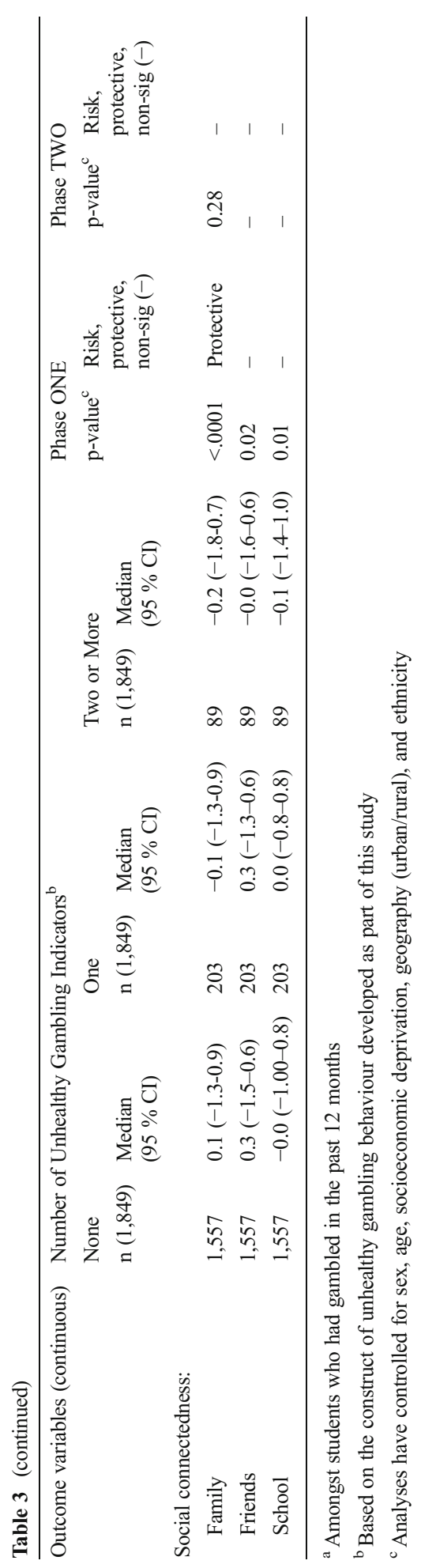


5 Well-Being Index - a short self-administered questionnaire that covers five-items relating to positive mood, vitality and general interests) (World Health Organization 1998) and family connectedness acted in a protective manner.

Multiple logistic regressions between the measure of 'unhealthy gambling' and the variables that fulfilled significant risk/protective functions were carried out to determine if these items maintained their risk/protective functions in the presence of each other (phase two analyses). As detailed in Tables 3 and 4, four variables were associated with an increased risk of 'unhealthy gambling' in Phase two, specifically: worried about and/or had tried to cut down on their gambling (OR 2.6 and OR 5.1); more accepting attitudes towards gambling (OR 4.2); gambled on EGMs, casinos, or horse/dog/sports ('TAB') betting in the past 12 months (OR 3.8 and OR 6.7); and, had attempted suicide in the past 12 months (OR 4.0 and OR 7.9). None of the investigated protective items continued to maintain a measureable protective role.

\section{Discussion}

\section{Summary of Main Findings}

Most students in this study had limited engagement with gambling activities. However, substantial proportions of students who had gambled in the past year reported factors that were indicative of unhealthy gambling, with these rates being comparable to those observed in the Youth'07 study (Rossen et al. 2011). Males, students from Māori, Pacific and Asian communities, those living in highly socio-economically deprived neighbourhoods, urban students and same/both-sex or not-sure attracted young people (i.e. sexual minority youth) are disproportionately at risk. Having more accepting attitudes towards gambling; gambling on EGMs, casinos, or horse/dog/sports betting in the past 12 months; being worried about and/or had tried to cut down on their gambling; and, attempting suicide in the past 12 months were associated with a higher risk of unhealthy gambling among a representative sample of secondary school students.

Table 4 Logistic regression models - odds ratios for significant risk factors as identified in Phase Two ${ }^{\mathrm{a}}$

\begin{tabular}{|c|c|c|c|}
\hline \multirow[t]{3}{*}{ Outcome variables (categorical) } & \multicolumn{3}{|c|}{ Number of Unhealthy Gambling Indicators ${ }^{\mathrm{b}}$} \\
\hline & None & One & Two or more \\
\hline & Odds ratio $(95 \% \mathrm{CI})$ & Odds ratio $(95 \% \mathrm{CI})$ & Odds ratio $(95 \% \mathrm{CI})$ \\
\hline \multicolumn{4}{|c|}{ Activities that student has gambled on (last 12 months): } \\
\hline EGMs/Casino/TAB betting & 1 & $3.8(2.6-5.5)$ & $6.7(3.7-12.1)$ \\
\hline \multicolumn{4}{|c|}{ Attitudes and social modelling of gambling: } \\
\hline More accepting of gambling & 1 & $1.2(0.8-1.9)$ & $4.2(2.1-8.6)$ \\
\hline \multicolumn{4}{|l|}{ Concerns about gambling: } \\
\hline Worried/cut-down & 1 & $2.6(1.7-4.0)$ & $5.1(3.0-8.6)$ \\
\hline \multicolumn{4}{|l|}{ Emotional health and wellbeing: } \\
\hline Suicide attempt & 1 & $4.0(2.3-7.2)$ & $7.9(4.2-14.9)$ \\
\hline
\end{tabular}

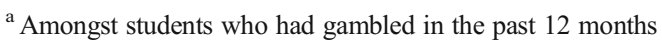

${ }^{\mathrm{b}}$ Based on the construct of unhealthy gambling behaviour developed as part of this study
} 
This research explored associations between a number of variables hypothesised to be a risk and/or protective factor of unhealthy gambling. The importance of supportive family environments was highlighted in Phase one of the analyses which indicated that family connectedness acted in a protective manner, whilst the family impacts of someone else's gambling (i.e. arguments in family, had to go without, bills not paid and dishonest acts) were all risk factors. The multivariate model suggests that while family connection acted in a protective manner, once other factors are accounted for in the model; it would appear that exposure to adult gambling behaviours and mental health indicators are more critical. These findings emphasise the need to consider family dynamics and support networks, and the importance of assessing the impacts of parental gambling on the children of adult clients with gambling-related issues when addressing the issue of unhealthy youth gambling (Clarke, Abbott, DeSouza, and Bellringer 2007).

The significant relationships between unhealthy gambling and other emotional/mental health issues are important indicators for clinicians, educators and policy makers to address. Students with unhealthy gambling practices were significantly more likely to report co-existing mental health issues (e.g. depression and suicide attempts) and other addictions/risky behaviours (e.g. use of alcohol and weekly cigarette smoking) emphasising the need for clinicians to consider unhealthy gambling alongside other health issues. The findings are consistent with Shead et al. (2010) who argued that many of the risk factors for unhealthy youth gambling predict a general behaviour syndrome that is encompassed by overall mental health problems. This aligns with research that has shown a tendency for clinically concerning health risk and emotional health concerns to cluster in young people (Noel et al. 2013). The authors argue that this demonstrates a need for comprehensive psychosocial assessments and the provision of appropriate services, particularly for 'at-risk' youth.

Moreover, the finding that young people with more accepting attitudes towards gambling are at greater risk of problems has implications for health promotion efforts. Social acceptability (by parents and peers) is recognised as an important socio-ecological driver of other risky behaviours in youth, including marijuana and illicit drug use, binge drinking and smoking (Bahr, Hoffmann, and Yang 2005; Simons-Morton and Farhat 2010). Efforts to adjust youth attitudes towards gambling will have to reflect an ecological approach that considers socialisation processes and takes into account the attitudes of parents, peers and society at large.

This research identified a number of important disparities based on demographic features, largely consistent with previous gambling research involving young people from New Zealand (Devlin 2011; Health Sponsorship Council 2012; Rossen et al. 2011). Consistent with research from Greece and Finland (Floros et al. 2013; Raisamo, Halme, Murto, and Lintonen 2013), gambling appears to play a more prominent role in the life of young males than females in New Zealand. Overall, the disproportionately higher percentages of youth gambling and/or unhealthy gambling behaviour amongst Māori, Pacific and Asian students, and students living in highly deprived neighbourhoods, corresponds with findings from adult-based gambling research in New Zealand (Abbott, Bellringer, Garrett, and Mundy-McPherson 2014; Abbott and Volberg 2000; Bellringer, Perese, Abbott, and Williams 2006; Devlin 2011; Perese, Bellringer, Williams, and Abbott 2009; Tu'itahi, Guttenbeil-Po'uhila, Hand, and Htay 2004). Sexual minority students were another population with a heightened risk of problematic gambling. These youth were significantly more likely to report unhealthy gambling compared to their exclusively opposite-sex attracted peers. To the authors' knowledge, this finding 
is unique; while sexuality and gambling has been explored in adults (Liao 2014) it has not previously been explored in relation to youth gambling. This finding does however correspond with prior research on substance use, where youth that were not exclusively opposite-sex attracted were, on average, $190 \%$ more likely to report substance use than heterosexual youth (Marshal et al. 2008). Specific strategies are required that address ethnic, sexuality and social disparities faced by certain populations vulnerable to unhealthy gambling.

Young people rarely seek formal help for gambling-related problems (Griffiths 2001; Gupta and Derevensky 2000). Nonetheless, research from Australia and North America has indicated that negative emotional states such as stress, depression and guilt are strong motivators for help-seeking amongst adults (Evans and Delfabbro 2005; Hodgins \& elGuebaly 2000), and research with New Zealand adults has shown that a lack of selfawareness (i.e. denial of gambling problems) is a barrier to help-seeking (Clarke et al. 2007). Of the students who were gambling at unhealthy levels in this study, more than half demonstrated self-awareness (i.e. they were worried about or had tried to cut down on their gambling). This self-awareness may be an important indicator that an appropriate opportunity exists to motivate a young person to address their gambling through a suitable intervention.

The host responsibility of gambling venues in New Zealand requires urgent improvement; despite legislation prohibiting minors from gambling on EGMs, casinos, and horse/dog/sports ('TAB') betting, significant proportions of students reported engaging in these intense forms of gambling. Moreover, involvement in these modes was associated with a high risk of unhealthy gambling - consistent with previous research highlighting the dangers of continuous modes of gambling (i.e. those with continuous/ immediate feedback cycles) (Abbott and Volberg 2000; Health Sponsorship Council 2012).

\section{Strengths and Limitations}

The data presented in this study are from a large nationally representative sample of secondary school students in New Zealand. This study utilised a unique non-dichotomous measure of problematic gambling which is advantageous as it reflects the more fluid nature of youth behavioural issues.

There are a number of limitations to the study. Young people who are disengaged from a mainstream school environment (e.g. students in alternative education programmes outside of mainstream schooling and young people who have 'dropped out' of school) are not represented in these findings. Moreover, only students who were at school on the day of the survey were included. Therefore the findings outlined in this paper may represent a more 'positive' view of gambling-related issues for New Zealand's youth, as evidence suggests that young people who are disengaged from mainstream education are not as healthy as their peers (Bovet, Viswanathan, Faeh, and Warren 2006; Clark et al. 2010; Denny, Clark, and Watson 2004). Additionally, the Youth'12 survey is a cross-sectional survey, and as such it is important to note that while a number of relationships/associations have been observed between variables, these are not necessarily indicative of cause and effect, and directionality cannot be determined. For instance, it is unclear if problematic gambling leads to associated financial and other issues, which then lead to depression or if gambling is driven by a pre-existing mental health issue. 


\section{Conclusions}

Unhealthy gambling impacts on a numerically small group, but is significantly problematic amongst certain New Zealand secondary school students and their families. Youth affected by unhealthy gambling are likely to have other social, addiction and emotional/mental health challenges.

Acknowledgments We would like to thank the students, staff and schools who took part in the survey. We would also like to acknowledge Sarah Masson - the Youth'12 project manager, and Toni Jardine - the Youth'12 administrator, and the members of the research team who implemented the survey in the participating schools. We also thank our steering and advisory groups for their guidance and support.

Funding The Youth'12 survey was funded by the New Zealand Ministries of Youth Development, Social Development, Health, Education, Justice, the Department of Labour, Families Commission, and the Alcohol Advisory Council. We would also like to acknowledge the support of Toshiba (Australia) Pty. Limited.

The report on which this study is based was funded by the Ministry of Health (Problem Gambling, Mental Health Service Improvement, Sector Capability and Implementation).

Informed Consent All procedures were in accordance with the ethical standards of the responsible committee on human experimentation (institutional and national) and with the Helsinki Declaration of 1975, as revised in 2000. Informed consent was obtained from all students for being included in the study.

Open Access This article is distributed under the terms of the Creative Commons Attribution 4.0 International License (http://creativecommons.org/licenses/by/4.0/), which permits unrestricted use, distribution, and reproduction in any medium, provided you give appropriate credit to the original author(s) and the source, provide a link to the Creative Commons license, and indicate if changes were made.

\section{References}

Abbott, M., \& Volberg, R. A. (2000). Taking the pulse on gambling and problem gambling in New Zealand: A report on phase one of the 1999 national prevalence survey (Report number three of the New Zealand Gaming Survey). Wellington: The Department of Internal Affairs.

Abbott, M., Bellringer, M., Garrett, N., \& Mundy-McPherson, S. (2014). New Zealand 2012 National Gambling Study: Gambling Harm and Problem Gambling. Report Number Two. Auckland: Gambling and Addictions Research Centre, Auckland University of Technology.

Bahr, S. J., Hoffmann, J. P., \& Yang, X. (2005). Parental and peer influences on the risk of adolescent drug use. The Journal of Primary Prevention, 26(6), 529-551.

Bellringer, M., Perese, L., Abbott, M., \& Williams, M. (2006). Gambling among pacific mothers living in New Zealand. International Gambling Studies, 6(2), 217-235.

Blinn-Pike, L., Worthy, S. L., \& Jonkman, J. N. (2010). Adolescent gambling: a review of an emerging field of research. Journal of Adolescent Health, 47(3), 223-236.

Bovet, P., Viswanathan, B., Faeh, D., \& Warren, W. (2006). Comparison of smoking, drinking, and marijuana use between students present or absent on the day of a school-based survey. Journal of School Health, 76(4), $133-137$.

Clark, C., \& Walker, D. M. (2009). Are gamblers more likely to commit crimes? an empirical analysis of a nationally representative survey of US young adults. International Gambling Studies, 9(2), $119-134$.

Clark, T., Smith, J., Raphael, D., Jackson, C., Denny, S., Fleming, T., . . . Crengle, S. (2010). Kicked out of school and suffering: The health needs of alternative education youth in New Zealand. Youth Studies Australia, 29(4), 10-17.

Clark, T. C., Fleming, T., Bullen, P., Crengle, S., Denny, S., Dyson, B., . . . The Adolescent Health Research Group. (2013). Youth'12 Prevalence Tables: The Health and Wellbeing of New Zealand Secondary School Students in 2012. Auckland: The University of Auckland.

Clarke, D., Abbott, M., DeSouza, R., \& Bellringer, M. (2007). An overview of help seeking by problem gamblers and their families including barriers to and relevance of services. International Journal of Mental Health and Addiction, 5(4), 292-306. 
Denny, S., Clark, T., \& Watson, P. (2004). The health of alternative education students compared to secondary school students: a New Zealand study. New Zealand Medical Journal, 117(1205), 112.

Denny, S., Milfont, T., Utter, J., Robinson, E., Ameratunga, S. N., Merry, S. N., . . Watson, P. D. (2008). Handheld internet tablets for school-based data collection. Biomedical Centre Research Notes, 1(52), 1-4.

Department of Internal Affairs. (2008). People's Participation in, and Attitudes to, Gambling, 1985-2005. Results of the 2005 survey. Wellington: The Department of Internal Affairs.

Derevensky, J., \& Gupta, R. (2000). Youth gambling: a clinical and research perspective. Journal of Gambling Issues, 2, 1-11.

Devlin, M. (2011). Technical report: Groups at risk of at-risk gambling. Wellington: Health Sponsorship Council.

Dickson, L., Derevensky, J. L., \& Gupta, R. (2008). Youth gambling problems: examining risk and protective factors. International Gambling Studies, 8(1), 25-47.

Evans, L., \& Delfabbro, P. H. (2005). Motivators for change and barriers to help-seeking in Australian problem gamblers. Journal of Gambling Studies, 21(2), 133-155.

Felsher, J. R., Derevensky, J. L., \& Gupta, R. (2003). Parental influences and social modelling of youth lottery participation. Journal of Community \& Applied Social Psychology, 13(5), 361-377.

Fisher, S. (1999). A prevalence study of gambling and problem gambling in British adolescents. Addiction Research and Theory, 7(6), 509-538.

Floros, G., Siomos, K., Fisoun, V., \& Geroukalis, D. (2013). Adolescent online gambling: the impact of parental practices and correlates with online activities. Journal of Gambling Studies, 29(1), $131-150$.

Floros, G., Paradisioti, A., Hadjimarcou, M., Mappouras, D. G., Karkanioti, O., \& Siomos, K. (2015). Adolescent online gambling in Cyprus: associated school performance and psychopathology. Journal of Gambling Studies, 31, 367-384.

Fortune, E. E., MacKillop, J., Miller, J. D., Campbell, W. K., Clifton, A. D., \& Goodie, A. S. (2013). Social density of gambling and its association with gambling problems: an initial investigation. Journal of Gambling Studies, 29, 329-342.

Goldstein, A. L., Faulkner, B., Cunningham, R. M., Zimmerman, M. A., Chermack, S., \& Walton, M. A. (2013). A latent class analysis of adolescent gambling: application of resilience theory. International Journal of Mental Health and Addiction, 11, 13-30.

Griffiths, M. (2001). Why don't adolescent problem gamblers seek treatment? The Electronic Journal of Gambling Studies: eGambling (Issue 5). Available: http:/www.camh.net/egambling/issue5/opinion/index. html).

Griffiths, M., \& Wood, R. T. (2000). Risk factors in adolescence: the case of gambling, videogame playing, and the internet. Journal of Gambling Studies, 16(2-3), 199-225.

Gupta, R., \& Derevensky, J. (2000). Adolescents with gambling problems: from research to treatment. Journal of Gambling Studies, 16(2/3), 315-342.

Hardoon, K., \& Derevensky, J. L. (2002). Child and adolescent gambling behavior: current knowledge. Clinical Child Psychology and Psychiatry, 7(2), 263-281.

Hardoon, K., Derevensky, J., \& Gupta, R. (2002). An Examination of the Influence of Familial, Emotional, Conduct, and Cognitive Problems, and Hyperactivity upon Youth Risk-taking and Adolescent Gambling Problems. Ontario: Ontario Problem Gambling Research Centre.

Health Sponsorship Council. (2012). New Zealanders' Knowledge, Views and Experience of Gambling and Gambling Harm: Results from the 2010 Health and Lifestyles Survey. Wellington, New Zealand: Health Sponsorship Council.Retrieved from Retrieved from http://www.hsc.org.nz/researchpublications.html

Hodgins, D. C., \& el-Guebaly, N. (2000). Natural and treatment assisted recovery from gambling problems: comparison of resolved and active gamblers. Addiction, 95(5), 777-789.

Huang, J.-H., \& Boyer, R. (2007). Epidemiology of youth gambling problems in Canada: a national prevalence study. Canadian Journal of Psychiatry / Revue Canadienne de Psychiatrie, 52(10), 657-665.

Huxley, J., \& Carroll, D. (1992). A survey of fruit machine gambling in adolescents. Journal of Gambling Studies, 8(2), 167-179.

Jackson, A. C., Dowling, N., Thomas, S. A., Bond, L., \& Patton, G. (2008). Adolescent gambling behaviour and attitudes: a prevalence study and correlates in an Australian population. International Journal of Mental Health and Addiction, 6(3), 325-352.

Lang, K. (2002). Measuring ethnicity in the New Zealand census. Wellington: Statistics New Zealand.

Liao, M. (2014). Problem Gambling Prevention Technical Assistance and Training Project: Problem Gambling and the Lesbian, Gay, Bisexual and Transgender Community. Retrieved 10 September, 2014, from http://www.nsgamingfoundation.org/uploads/Research/Problem\%20Gambling\%20and\% 20the\%20LGBT.pdf 
Marshal, M. P., Friedman, M. S., Stall, R., King, K. M., Miles, J., Gold, M. A., . . Morse, J. Q. (2008). Sexual orientation and adolescent substance use: a meta-analysis and methodological review. Addiction, 103(4), 546-556.

Moodie, C., \& Finnigan, F. (2006). Prevalence and correlates of youth gambling in Scotland. Addiction Research and Theory, 14(4), 365-385.

Noel, H., Denny, S., Farrant, B., Rossen, F., Teevale, T., Clark, T., . . . Fortune, S. (2013). Clustering of adolescent health concerns: a latent class analysis of school students in New Zealand. Journal of Paediatrics and Child Health, 49(11), 935-941.

Perese, L., Bellringer, M., Williams, M., \& Abbott, M. (2009). Two years on: gambling amongst pacific mothers living in New Zealand. Pacific Health Dialogue, 15(1), 55-67.

Raisamo, S., Halme, J., Murto, A., \& Lintonen, T. (2013). Gambling-related harms among adolescents: a population-based study. Journal of Gambling Studies, 29, 151-159.

Rossen, F., Tse, S., \& Vaidya, R. (2009). New Zealand Asian and youth gambling: a secondary analysis of data from the health sponsorship council 2006/07 gaming and betting attitudes survey. Auckland: University of Auckland.

Rossen, F., Butler, R., \& Denny, S. (2011). An Exploration of Youth Participation in Gambling and the Impact of Problem Gambling on Young People in New Zealand. Auckland: Centre for Gambling Studies, Auckland UniServices Limited, The University of Auckland.

Rossen, F., Fleming, T., Lucassen, M., Denny, S., Peiris-John, R., Teevale, T., . . . The Adolescent Health Research Group. (2013). The Health and Wellbeing of New Zealand Secondary School Students in 2012: Youth Gambling. Auckland, New Zealand: The University of Auckland.

Salmond, C., Crampton, P., Sutton, F., \& Atkinson, J. (2006 ). NZDep2006 Census Area Unit Data. [3 April, 2013]: Available from: http://www.otago.ac.nz/wellington/research/hirp/otago020194.html.

SAS Institute Inc. (2011). SAS/STAT Software (Version 9.3). Cary, NC: SAS International.

Shead, N. W., Derevensky, J. L., \& Gupta, R. (2010). Risk and protective factors associated with youth problem gambling. International Journal of Adolescent Medicine and Health, 22(1), 39-58.

Simons-Morton, B., \& Farhat, T. (2010). Recent findings on peer group influences on adolescent substance Use. Journal of Primary Prevention, 31(4), 191-208.

Splevins, K., Mireskandari, S., Clayton, K., \& Blaszczynski, A. (2010). Prevalence of adolescent problem gambling, related harms and help-seeking behaviours among an Australian population. Journal of Gambling Studies, 26(2), 189-204.

Statistics New Zealand. (2005). Statistical Standard for Ethnicity. [3 April, 2013] Available from: http://www. stats.govt.nz/surveys_and_methods/methods/classifications-and-standards/classification-related-statsstandards/ethnicity.aspx.

Stinchfield, R. (2000). Gambling and correlates of gambling among Minnesota public school students. Journal of Gambling Studies, 16(2-3), 153-173.

Stinchfield, R. (2001). A comparison of gambling by Minnesota public school students in 1992, 1995, and 1998. Journal of Gambling Studies, 17(4), 273-296.

Tu'itahi, S., Guttenbeil-Po'uhila, Y., Hand, J., \& Htay, T. (2004). Gambling issues for Tongan people in Auckland, Aotearoa-New Zealand. Journal of Gambling Issues, (12).

Turchi, R. M., \& Derevensky, J. L. (2006). Youth gambling: not a safe bet. Current Opinion in Pediatrics, 18(4), $454-458$.

Turner, N. E., Macdonald, J., Bartoshuk, M., \& Zangeneh, M. (2008). Adolescent gambling behaviour, attitudes, and gambling problems. International Journal of Mental Health and Addiction, 6(2), 223-237. doi:10.1007/ s11469-007-9117-1.

Valentine, G. (2008). Literature review of children and young people's gambling. Birmingham: Gambling Commission.

Volberg, R. A., Abbott, M., Ronnberg, S., \& Munck, I. M. (2001). Prevalence and risks of pathological gambling in Sweden. Acta Psychiatrica Scandinavica, 104(4), 250-256.

Volberg, R., Gupta, R., Griffiths, M., Ólason, D., \& Delfabbro, P. (2010). An international perspective on youth gambling prevalence studies. International Journal of Adolescent Medicine and Health, 22(1), 3-38.

Welte, J. W., Barnes, G. M., Tidwell, M.-C. O., \& Hoffman, J. H. (2008). The prevalence of problem gambling among U.S. adolescents and young adults: results from a national survey. Journal of Gambling Studies, 24(2), 119-133.

World Health Organization. (1998). WHO (Five) Well-Being Index (1998 Version). Available at http://www.who5.org. 